\title{
Relationship between the Apolipoprotein Al, B gene polymorphism and the risk of non-traumatic osteonecrosis
}

\author{
Ji-Min Yin ${ }^{1 \dagger}$, Zhao Liu², Shi-Chang Zhao ${ }^{1 \dagger}$, Yan-Jie Guo ${ }^{1}$ and Zhong-Tang Liu* ${ }^{1 *}$
}

\begin{abstract}
Background: Previous studies suggested that Apolipoprotein Al (ApoAl) and apolipoprotein B (ApoB) gene polymorphisms may result in lipid metabolism disorders. Genetic polymorphisms in these genes may be associated with the occurrence of osteonecrosis.

Methods: We designed a case-control study including 429 patients of osteonecrosis and 368 age- and sex-matched control subjects. Polymerase chain reaction was used to amplify the DNA fragments in promoter -75 G > A of ApoAl gene and EcoR I, Xba I and 3'-VNTR of ApoB gene in osteonecrosis patients and healthy controls. We utilized polymerase chain reaction-restriction fragment length polymorphism (PCR-RFLP) method to genotype these four single nucleotide polymorphisms (SNPS).

Results: For -75 G > A polymorphism of ApoAl, AA genotype frequency (0.501) was significantly higher in patients with osteonecrosis than that in control $(0.462)$ subjects $(P<0.001)$, GA genotype frequency $(0.170)$ was significantly lower than that in the control $(0.310)$ group $(P<0.0001)$. In osteonecrosis patients, the odds ratio $(\mathrm{OR})$ of $A$ allele was 3.932 (95\% Cl: 3.0847 5.0123), which suggested that subjects carrying A allele of promoter region -75 G > A of ApoAl gene had higher susceptibility to osteonecrosis than $\mathrm{G}$ allele carriers. The genotype and allele frequency distributions showed no significant difference in EcoR I, Xba land 3'-VNTR loci of ApoB gene between the osteonecrosis group and control group.
\end{abstract}

Conclusion: Our study suggested that ApoAl gene $-75 \mathrm{G}>$ A polymorphism may be associated with susceptibility to osteonecrosis in Chinese population. However, our results need further investigation with large sample size and various populations.

Keywords: Apolipoprotein Al, Apolipoprotein B, Non-traumatic osteonecrosis, Gene polymorphism, Molecular epidemiology

\section{Introduction}

Osteonecrosis is one kind of orthopedic refractory disease and is divided into traumatic and non-traumatic one. Non-traumatic osteonecrosis, with rapid progression, is common seen in young people [1]. Currently, the whole population of osteonecrosis is about 7 million people in China, and new cases have reached 100-200 thousand each year [2]. Previous studies indicated that the abnormal lipid metabolism is known to be the main

\footnotetext{
* Correspondence: zcq791306@163.com

${ }^{\dagger}$ Equal contributors

'Department of Orthopedic Surgery, Shanghai Sixth People's Hospital, Shanghai Jiaotong University, No.600 Yishan Road, Shanghai 200233, China Full list of author information is available at the end of the article
}

pathogenesis of osteonecrosis [3]. Heavy drinking and excessive use of corticosteroids may result in abnormal lipid metabolism in general populations [4]. Therefore, among the etiologies of osteonecrosis, both of them were commonly considered to have the same pathogenesis. Studies showed that the incidence of coronary heart disease (CHD) was associated with abnormal ApoAI and ApoB levels resulting from apoAI and apoB gene polymorphisms [5-7]. However, the relationship between these polymorphisms and non-traumatic osteonecrosis has not been systematically studied. In 2007, Hirata et al. [8] performed a case-control study to reveal the relation between ApoAI and ApoB genetic polymorphisms 
and osteonecrosis in a Japanese population. In their study, four SNPs including C7623T and G12619A for the ApoB gene and G75A and C83T for the ApoAI gene were analyzed using PCR-RFLP and TaqMan realtime PCR method. The authors found C7623T polymorphism of ApoB gene was associated with osteonecrosis. Subsequently, Wang et al. [9] found -75 G > A polymorphism was associated with osteonecrosis in Chinese population. However, the sample sizes of these two studies were very small.

Up to date, a number of SNPs of ApoAI and ApoB were reported, such as $-75 \mathrm{G}>\mathrm{A},+75 \mathrm{bp}$ and +83 bp loci of Apo AI gene, Eco RI loci, Xba I loci and 3'-VNTR of Apo $B$ gene, which were reported to be associated with several disease [8-13]. To further clarify the association of ApoAI and ApoB genetic polymorphism and osteonecrosis, we designed a larger sample-size case-control study.

\section{Subjects and methods \\ Ethics}

The present study has been performed with the approval of the ethics committee of Shanghai Jiaotong University and was in compliance with the Helsinki Declaration. The informed consents of the study were collected from all the candidate subjects.

\section{Subjects}

All the patients were selected from November 2001 to September 2013 in Shanghai Sixth People's Hospital. All the patients were consistent with the diagnostic criteria of osteonecrosis proposed in 1995 by Mont et al. [14]. They were all confirmed by clinical diagnosis, double hip X-ray image, CT scan or MRI examination. A total of 429 cases including 326 male and 103 female with the average age of $44.6 \pm 11.3$ years were included. Exclusion criteria: 1) Primary disease in serious condition which required hormone replacement therapy. 2) Drugs use which can affect the lipid metabolism and liver enzyme in patients. 3) It did not meet the diagnostic criteria of osteonecrosis or patients with traumatic osteonecrosis and other hip diseases. 4) Patients who were reluctant to be included in this study.

The subjects in the control group were selected from the same hospital. They did not have osteonecrosis and other related diseases. A total of 368 subjects including 278 male and 90 female were selected as the control group, they were aged $44.7 \pm 11.7$ years old. They have same exposure situation as the case group in Shanghai Sixth People's Hospital, and have the associated primary disease and accept the system hormone therapy with a clear hormone amount and time of more than one month, and after a 1-year follow-up, no osteonecrosis was found.
Subject with poor compliance, incomplete clinical data and vague diagnosis were excluded.

\section{Methods \\ Blood collection and DNA preparation}

Blood samples were collected using a standard venipuncture technique and EDTA-containing tubes.DNA was extracted from peripheral vein blood leukocytes using a whole blood genome extraction kit (Beijing Boiteke Corporation, Beijing, China).

\section{Primers and genotyping}

The primers were designed according to previous literatures [15-19]. All primers were synthesed by Shanghai Sangon Biological Engineering Company (Shanghai China). Genotyping methods were performed according to references [16-19]. Briefly, polymerase chain reaction (PCR) was performed in a volume of $25 \mathrm{ml}$ containing $200 \mathrm{ng}$ genomic DNA. The amounts of $\mathrm{Mg}^{2+}, \mathrm{dNTP}$, and DNA polymerase (Bangalore Genei, India) used in each reaction were $1.5 \mathrm{mM}, 200 \mathrm{mM}$, and $1 \mathrm{U}$, respectively. The thermal cycles started with $94^{\circ} \mathrm{C}$ for $4 \mathrm{~min}$ and were followed by 35 cycles of $94^{\circ} \mathrm{C}$ for $30 \mathrm{~s}, 55^{\circ} \mathrm{C}$ for $30 \mathrm{~s}$, and $72^{\circ} \mathrm{C}$ for $30 \mathrm{~s}$. A total volume of $20 \mathrm{ul}$ containing $20 \mathrm{U}$ endonuclease was added directly to the PCR product and digested at $37^{\circ} \mathrm{C}$ overnight. After electrophoresis, the digested products were visualized on a $3 \%$ polyacrylamide gel with ethidium bromide staining. The genotyping results were shown in Figure 1.

\section{Statistical analysis}

Data were analyzed using SPSS 17.0 software package (Chicago, IL, USA). The genotype and allele frequencies were calculated by direct counting method. The differences of genotype and allele distributions between case and control groups were compared using $x^{2}$ test, OR value and its $95 \% \mathrm{CI}$ was calculated according to logistic regression analysis. Single-SNP effects with continuous variables were analyzed using general linear model (GLM). Normality was assessed by plotting the residuals. Statistical significance was set at $\mathrm{p}<0.05$.

\section{Results}

\section{Characteristics of participants}

The characteristics of 429 patients and 368 control subjects were shown in Table 1. After the statistical analysis, there were no significant differences in the distribution of age, sex, body mass index (BMI), GLU, TC and HDL-C between the two groups. However, there were significant differences in TG and LDL-C between these two groups. 


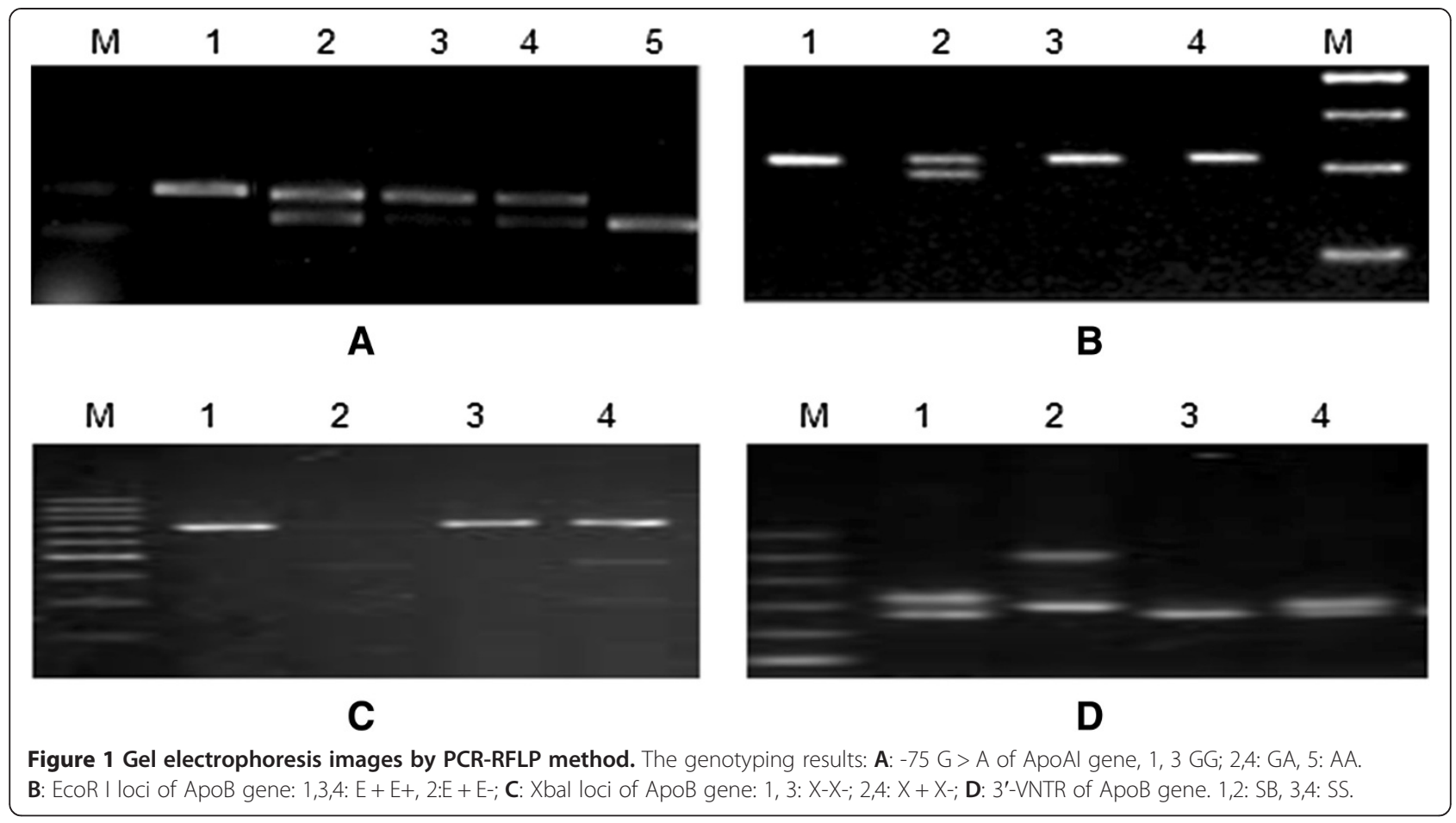

\section{Hardy-Weinberg equilibrium}

The genotype distribution was in Hardy-Weinberg equilibrium in both case group and control group (both $\mathrm{P}>0.05$, data not shown).

\section{Genotype and allele frequency distributions}

As shown in Table 2, for the -75 G > A SNP of apoAI gene, AA genotype frequency (0.501) was significantly higher in patients with osteonecrosis than that in control (0.462) subjects $(P<0.001)$, GA genotype frequency $(0.170)$ was significantly lower than that in the control $(0.310)$ group $(P<0.0001)$. The genotype and allele frequency distribution in EcoR I, Xba I and 3'-VNTR of apoB gene were also shown in Table 2. For the EcoR I, Xba I and 3'-VNTR of apoB gene, $\mathrm{E}+\mathrm{E}+, \mathrm{X}-\mathrm{X}$ - and $\mathrm{SS}$ genotypes were more common in both osteonecrosis group and control group. However, for these three loci, the genotype and allele frequencies distribution between the two groups showed no significant difference (all $P>0.05$ ).

In osteonecrosis patients, the OR of A allele was 3.932 (95\% CI: $3.0847 \sim 5.0123$ ), which suggested that subjects carrying A allele of promoter region - $75 \mathrm{G}>\mathrm{A}$ of ApoAI gene had higher susceptibility to osteonecrosis than subjects carrying $\mathrm{G}$ allele.

In addition, age and sex adjusted intergenotypic variations in lipid, lipoprotein and apolipoprotein A-I levels with respect to apoAI-75 G/A polymorphism has been summarized in Table 3. Rare A allele carriers were associated with lower levels of HDL in both osteonecrosis patients and control subjects (both $P<0.0001$ ). Likewise, A allele carriers had lower levels of apoA-I as compared to GG individuals in the osteonecrosis patients group and control group $(\mathrm{P}<0.0001)$.

\section{Discussion}

In the present study, we found that in patients with osteonecrosis, AA genotype frequency of promoter region $-75 \mathrm{G}>\mathrm{A}$ in apoAI gene was significantly higher than that in the control group $(P<0.0001)$, the GA genotype frequency was significantly lower than that in the control group $(P<0.0001)$. However, we did not find significant differences in EcoR I, Xba I and $3{ }^{\prime}$-VNTR region of ApoB gene between patients and control group.

Table 1 Characteristics of the participants

\begin{tabular}{cccccccccc}
\hline Groups & $\mathbf{N}$ & Age (years) & Gender & BMI Kg/m & GLU (mmol/L) & TG (mmol/L) & TC (mmol/L) & HDL-C (mmol/L) & LDL-C (mmol/L) \\
\hline ONFH group & 429 & $44.6 \pm 11.3$ & $326 / 103$ & $24.6 \pm 3.8$ & $5.4 \pm 1.6$ & $2.1 \pm 1.0$ & $4.8 \pm 2.5$ & $1.5 \pm 0.9$ & $2.7 \pm 1.4$ \\
Control group & 368 & $44.7 \pm 11.7$ & $278 / 90$ & $24.9 \pm 3.7$ & $5.3 \pm 1.5$ & $1.7 \pm 1.1$ & $4.7 \pm 1.9$ & $1.4 \pm 0.7$ & $2.4 \pm 1.6$ \\
$P$ & & 0.903 & 0.949 & 0.261 & 0.352 & $<0.001$ & 0.531 & 0.084 & 0.005 \\
\hline
\end{tabular}

Note: $\mathrm{BMI}=$ Body mass index; GLU = Glucose; TC = Total cholesterol; LDL-C = Low-density lipoprotein-cholesterol; LDL-C = High-density lipoprotein-cholesterol; TG = Triglycerides. 
Table 2 Distributions of ApoAl and ApoB genotypes

\begin{tabular}{|c|c|c|c|c|c|c|c|c|c|c|}
\hline \multirow[t]{2}{*}{ SNPs } & \multirow[t]{2}{*}{ Allels (1/2) } & \multirow[t]{2}{*}{ Groups } & \multicolumn{3}{|c|}{ Genotypes (n, \%) } & \multirow[t]{2}{*}{$P$ value } & \multicolumn{2}{|c|}{ Allele (n, \%) } & \multirow[t]{2}{*}{ OR $(95 \% \mathrm{Cl})$} & \multirow[t]{2}{*}{$P$ value } \\
\hline & & & $1 / 1$ & $1 / 2$ & $2 / 2$ & & 1 & 2 & & \\
\hline \multirow[t]{2}{*}{$-75 G>A$} & $\mathrm{G} / \mathrm{A}$ & Case & $215(0.501)$ & $73(0.170)$ & $141(0.329)$ & $<0.0001$ & $503(0.586)$ & $355(0.414)$ & $3.9321(3.0847 \sim 5.0123)$ & $<0.0001$ \\
\hline & & Control & $170(0.462)$ & $114(0.310)$ & $84(0.228)$ & & $624(0.848)$ & $112(0.152)$ & & \\
\hline \multirow[t]{2}{*}{ EcoR I } & $\mathrm{E}+/ \mathrm{E}-$ & Case & $391(0.911$ & $38(0.089)$ & - & 0.151 & $820(0.956)$ & $38(0.044)$ & $0.7288(0.4667 \sim 1.1381)$ & 0.163 \\
\hline & & Control & $324(0.880)$ & $44(0.120)$ & - & & $692(0.940)$ & $44(0.060)$ & & \\
\hline \multirow[t]{2}{*}{ Xba I } & $X-/ X+$ & Case & $394(0.918)$ & $35(0.082)$ & - & 0.153 & $823(0.959)$ & $35(0.041)$ & $0.7209(0.4541 \sim 1.1445)$ & 0.164 \\
\hline & & Control & $327(0.889)$ & $41(0.111)$ & - & & $695(0.944)$ & $41(0.056)$ & & \\
\hline \multirow[t]{2}{*}{ 3'-VNTR } & $\mathrm{S} / \mathrm{B}$ & Case & $336(0.783)$ & $93(0.217)$ & - & 0.306 & $765(0.892)$ & $93(0.108)$ & $1.1752(0.8463 \sim 1.6318)$ & 0.335 \\
\hline & & Control & $299(0.813)$ & $69(0.187)$ & - & & $667(0.933)$ & $69(0.067)$ & & \\
\hline
\end{tabular}

1: Represent common allele; 2: Represent rare allele.

Our finding indicated that genetic polymorphism of ApoAI may be associated with risk of osteonecrosis.

At present, it is believed that the abnormal lipid metabolism and intravascular coagulation composed the main pathogenesis of osteonecrosis [3]. Glucocorticoid can cause lipid metabolism abnormality and produce hyperlipidemia via the body lipid mobilization and the blood lipid inhibition in organization of cells [20]. Hyperlipidemia affected the microcirculation of the femoral head to result in femoral necrosis from multiple links, such as affecting blood coagulation solvent systems, influencing bone fat embolism, and affecting the formation of bone micro-thrombosis [21,22]. Apo AI is the major component of high-density lipoprotein protein which can regulate the high-density lipoprotein metabolism and cholesterol transport in plasma via regulating enzyme activity, receptor activity and diacylglycerol/protein kinase C (DG / PKC) pathway. Apo AI gene is located on the long arm of chromosome 11, and has multiple restriction

Table 3 Comparison of lipids levels between each genotype

\begin{tabular}{|c|c|c|c|c|c|}
\hline Parameters & Groups & GG & GA/AA & $\mathrm{P}^{*}$ & $P^{* *}$ \\
\hline \multirow[t]{2}{*}{$\overline{\mathrm{TC}}(\mathrm{mg} / \mathrm{dl})$} & Case & $\begin{array}{l}4.9 \pm 2.2 \\
(n=215)\end{array}$ & $\begin{array}{l}4.7 \pm 2.3 \\
(n=214)\end{array}$ & 0.358 & 0.765 \\
\hline & Control & $\begin{array}{l}4.7 \pm 2.4 \\
(n=170)\end{array}$ & $\begin{array}{l}4.6 \pm 2.2 \\
(n=198)\end{array}$ & 0.677 & 0.543 \\
\hline \multirow[t]{2}{*}{ LDL-C (mg/dl) } & Case & $2.8 \pm 1.1$ & $2.6 \pm 1.3$ & 0.086 & 0.077 \\
\hline & Control & $2.5 \pm 1.2$ & $2.3 \pm 1.4$ & 0.146 & 0.714 \\
\hline \multirow[t]{2}{*}{$\mathrm{HDL}-\mathrm{C}(\mathrm{mg} / \mathrm{dl})$} & Case & $1.7 \pm 0.9$ & $1.3 \pm 0.7$ & $<0.0001$ & $<0.0001$ \\
\hline & Control & $1.6 \pm 1.0$ & $1.4 \pm 0.8$ & $<0.0001$ & $<0.0001$ \\
\hline \multirow[t]{2}{*}{$\mathrm{TG}(\mathrm{mg} / \mathrm{dl})$} & Case & $2.2 \pm 1.0$ & $2.1 \pm 0.8$ & 0.254 & 0.198 \\
\hline & Control & $1.8 \pm 0.9$ & $1.7 \pm 1.0$ & 0.317 & 0.177 \\
\hline \multirow[t]{2}{*}{ ApoA-I $(g / l)$} & Case & $0.99 \pm 0.13$ & $0.86 \pm 0.12$ & $<0.0001$ & $<0.0001$ \\
\hline & Control & $0.94 \pm 0.14$ & $0.85 \pm 0.11$ & $<0.0001$ & $<0.0001$ \\
\hline
\end{tabular}

Note: $\mathrm{TC}=$ Total cholesterol; LDL-C = Low-density lipoprotein-cholesterol; LDL-C = High-density lipoprotein-cholesterol; TG = Triglycerides; ApoA-I = Apolipoprotein A-I; *before adjustment; **after adjustment. enzyme sites. Previous studies found that at the start site of human Apo AI gene transcription, G/A polymorphism existed at upstream -75 bp regions, this polymorphism was located at GC-rich region in ApoAI gene promoter, and the GC-rich region was the regulatory elements of Apo AI gene transcription. When the sequence changed, the gene transcription and expression will be affected, and Apo AI synthesis would be affected. ApoAI gene structure changed and affected the molecular structure of Apo AI and the generation and the release rate into the blood. Thereby it will affect the anti-atherosclerotic function of the blood ApoAI and high-density lipoprotein cholesterol levels, the lipid metabolism disorders would easily occur. Al-Bustan et al. reported a significant association of the APOAI $-75 \mathrm{G}>\mathrm{A}$ polymorphism with increased serum LDL-C. Multivariate analysis showed that APOAI -75 G > A was an independent predictive factor when controlling for age, sex and BMI for both LDL-C and TC levels. In the present study, our data revealed that ' $\mathrm{A}$ ' allele carriers were associated with lower HDL levels as compared to GG homozygous in patients $(18.8 \%$ lower, $P<0.0001)$ and control subjects $(16.6 \%$ lower, $P<0.0001)$. Also, apoA-I levels were found to be lower in GA and AA individuals as compared to GG in the patients (13.1\% lower, $P<0.0001)$ and control subjects $(9.6 \%$ lower, $P<0.0001)$.

ApoB was the component of lipoprotein (a), chylomicrons, very low density lipoproteins and intermediate density lipoprotein, it was the only structural protein of LDL. It mainly combined with cholesterol to form the low-density lipoprotein and recognized the low-density lipoprotein receptor, which played an important role in the process of transportation and metabolism of lipids. The apoB gene polymorphism can affect the plasma TC, LDL and ApoB levels [23]. Previous studies indicated that Xba I, EcoR I and 3'-VNTR in ApoB gene were associated with lipid metabolism and related diseases $[24,25]$. However, in the present study, we did not found association of these SNPs in ApoB gene and osteonecrosis. 
Although we found a positive association between $-75 \mathrm{G}>\mathrm{A}$ polymorphism and osteonecrosis, the present study was limited by the relatively small sample size. This may have led to weak statistical significance and wide CIs when estimating odds ratios. In addition, we did not perform functional study of these SNPs, which may be another limitation of our study.

\section{Conclusion}

In conclusion, this study showed that $-75 \mathrm{G}>\mathrm{A}$ polymorphism in ApoAI gene may be associated with osteonecrosis in Han Chinese population.

\section{Competing interests}

The authors declare that they have no competing interests.

\section{Authors' contributions}

JMY, LZ and SCZ carried out the molecular genetic studies and drafted the manuscript. YJG and ZTL carried out the genotyping. YJG, JMY, and ZTL participated in the design of the study and performed the statistical analysis. All authors read and approved the final manuscript.

\section{Author details}

${ }^{1}$ Department of Orthopedic Surgery, Shanghai Sixth People's Hospital, Shanghai Jiaotong University, No.600 Yishan Road, Shanghai 200233, China. 2Department of hematology, Shanghai Rui Jin Hospital, Shanghai Jiao Tong University School of Medicine, Shanghai, China.

Received: 18 May 2014 Accepted: 30 August 2014

Published: 23 September 2014

\section{References}

1. Zhang $H$, Xiao $F$, Liu $Y$, Zhao D, Shan $Y$, Jiang $Y$ : A higher frequency of peripheral blood activated $B$ cells in patients with non-traumatic osteonecrosis of the femoral head. Int Immunopharmacol 2014, 20(1):95-100.

2. Li ZR: Scientific diagnosis and treatment of femoral head necrosis. Zhongguo Xiufu Chongjian Waike Zazhi 2005, 19(9):685-686 (In Chinese)

3. Gangji V, De Maertelaer V, Hauzeur JP: Autologous bone marrow cell implantation in the treatment of non-traumatic osteonecrosis of the femoral head: Five year follow-up of a prospective controlled study. Bone 2011, 49(5):1005-1009.

4. Powell C, Chang C, Gershwin ME: Current concepts on the pathogenesis and natural history of steroid-induced osteonecrosis. Clin Rev Allergy Immunol 2011, 41(1):102-113.

5. Starklint H, Lausten GS, Arnoldi CC: Microvascular obstruction in avascular necrosis. Immunohistochemistry of 14 femoral heads. Acta Orthop Scand 1995, 66(1):9-12.

6. Reguero JR, Cubero GI, Batalla A, Alvarez V, Hevia S, Cortina A, Coto E: Apolipoprotein $\mathrm{Al}$ gene polymorphisms and risk of early coronary disease. Cardiology 1998, 90(3):231-235.

7. Huang G, Zhong H, Re HM, Mao HW, Niu Q, Chi YH: Coalition of DNA polymorphisms of $\mathrm{ApoB}$ and $\mathrm{ApoAl}$ genes is related with coronary artery disease in Kazaks. J Geriatr Cardiol 2012, 9(1):33-37.

8. Hirata T, Fujioka M, Takahashi KA, Arai Y, Asano T, Ishida M, Kuribayashi M, Akioka K, Okamoto M, Yoshimura N, Satomi Y, Nishino H, Fukushima W, Hirota Y, Nakajima S, Kato S, Kubo T: ApoB C7623T polymorphism predicts risk for steroid-induced osteonecrosis of the femoral head after renal transplantation. J Orthop Sci 2007, 12(3):199-206.

9. Wang $X Y$, Niu XH, Chen WH, Lin N, Song JN, Chen B, Jin H: Effects of apolipoprotein $A 1$ and $B$ gene polymorphism on avascular necrosis of the femoral head in Chinese population. Zhongguo Gu Shang 2008, 21(2):99-102 (in Chinese).

10. Hao J, He XD: Haplotype analysis of ApoAl gene and sepsis-associated acute lung injury. Lipids Health Dis 2014, 13:79.

11. Biswas S, Ghoshal PK, Halder B, Ganguly K, DasBiswas A, Mandal N Apolipoproteins $\mathrm{Al} / \mathrm{B} / \mathrm{E}$ gene polymorphism and their plasma levels in patients with coronary artery disease in a tertiary care-center of Eastern India. Indian Heart J 2013, 65(6):658-665.

12. Al-Bustan SA, Al-Serri AE, Annice BG, Alnaqeeb MA, Ebrahim GA: Re-sequencing of the APOAl promoter region and the genetic association of the $-75 G>A$ polymorphism with increased cholesterol and low density lipoprotein levels among a sample of the Kuwaiti population. BMC Med Genet 2013, 14:90.

13. Rebhi L, Kchok K, Omezzine A, Kacem S, Rejeb J, Ben HadjMbarek I, Belkahla R, Boumaiza I, Moussa A, Ben Rejeb N, Nabli N, Boughzala E, Ben Abdelaziz A, Bouslama A: Six lipoprotein lipase gene polymorphisms, lipid profile and coronary stenosis in a Tunisian population. Mol Biol Rep 2012, 39(11):9893-9901.

14. Mont MA, Hungerford DS: Non-traumatic avascular necrosis of the femoral head. J Bone and Joint Surg 1995, 77:459-474.

15. Padmaja N, Kumar MR, Adithan C: Association of polymorphisms in apolipoprotein A1 and apolipoprotein B genes with lipid profile in Tamilian population. Indian Heart J 2009, 61(1):51-54.

16. Chen ES, Mazzotti DR, Furuya TK, Cendoroglo MS, Ramos LR, Araujo LQ, Burbano RR, de Arruda Cardoso Smith M: Apolipoprotein A1 gene polymorphisms as risk factors for hypertension and obesity. Clin Exp Med 2009, 9(4):319-325.

17. Srivastava N, Prakash J, Srivastava A, Agarwal CG, Pant DC, Mittal B: Association of apolipoprotein $B$ Xbal gene polymorphism and lipid profile in northern Indian obese. Indian J Hum Genet 2013, 19(1):26-31.

18. Hu P, Qin YH, Jing CX, Lei FY, Chen P, Li MF: Association of polymorphisms at restriction enzyme recognition sites of apolipoprotein $B$ and $E$ gene with dyslipidemia in children undergoing primary nephrotic syndrome. Mol Biol Rep 2009, 36(5):1015-1021.

19. Paulweber B, Friedl W, Krempler F, Humphries SE, Sandhofer F: Association of DNA polymorphism at the apolipoprotein B gene locus with coronary heart disease and serum very low density lipoprotein levels. Arteriosclerosis 1990, 10(1):17-24.

20. Liebberman JR, Jeny DJ, Mont MA, Aaron RK, Callaghan JJ, Rayadhyaksha A, Urbaniak JR: Osteonecrosis of the Hip: management in the twenty-first centuy. Bone and Joint Surg 2002, 84(3):834-853.

21. Glueck CJ, Freiberg RA, Fontaine RN, Tracy T, Wang P: Hypofibrinolysis, Thrombophil-ia. Osteonecrosis Clin Orthop 2001, 386:19.

22. Phemister DB: The classic: repair of bone in the presence of aseptic necrosis resulting from fractures, transplantations, and vascular obstruction. Clin Orthop Relat Res 2008, 466(5):1021-1033.

23. Nikolajevic Starcevic J, Santl Letonja M, Praznikar ZJ, Makuc J, Vujkovac AC, Petrovic D: Polymorphisms Xbal (rs693) and EcoRI (rs1042031) of the $A p o B$ gene are associated with carotid plaques but not with carotid intima-media thickness in patients with diabetes mellitus type 2 . Vasa 2014, 43(3):171-180

24. Hu P, Hu B, Qin YH, Lu L, Li ZQ, Tao LQ, Pei Q, Chen J: Serum lipid abnormalities are not associated with apoB 3' VNTR polymorphism in nephrotic children. Genet Mol Res 2013, 12(1):765-774.

25. Takeuchi F, Isono M, Katsuya T, Yokota M, Yamamoto K, Nabika T, Shimokawa K, Nakashima E, Sugiyama T, Rakugi H, Yamaguchi S, Ogihara T, Yamori Y, Kato N: Association of genetic variants influencing lipid levels with coronary artery disease in Japanese individuals. PLOS One 2012, 7:e46385.

doi:10.1186/1476-511X-13-149

Cite this article as: Yin et al:: Relationship between the Apolipoprotein $\mathrm{Al}, \mathrm{B}$ gene polymorphism and the risk of non-traumatic osteonecrosis. Lipids in Health and Disease 2014 13:149. 